\title{
O ensino de filosofia na Educação Básica: uma problematização à luz da filosofia antiga
}

\author{
Augusto Rodrigues* \\ Universidade Estadual Paulista Júlio de Mesquita Filho \\ Rodrigo Pelloso Gelamo** \\ Universidade Estadual Paulista Júlio de Mesquita Filho
}

Resumo O objetivo deste texto consiste em problematizar os limites da filosofia na Educação Básica, uma vez que o ensino de filosofia na atualidade propicia uma formação bastante empobrecida. De fato, o que acontece em sala de aula é uma formação restrita à ordem da compreensão, assimilação e repetição dos discursos filosóficos. Por um lado, ensinar consiste no movimento de transmissão das representações que o professor tem de determinado recorte da história da filosofia. Por outro, aprender seria reproduzir aquilo que foi transmitido, aplicando tais representações como fórmulas para se pensar determinadas questões. A partir deste contexto escolar, começa-se a problematizar a efetividade da transmissão na construção de uma formação minimamente filosófica, pois é questionado se é a apropriação discursiva que fundamentaria este processo formativo. Tem-se como hipótese que não é a posse de discursos o que garantiria uma formação em filosofia e que este modo de formar não encontra ressonância na própria tradição filosófica. Para tanto, recuperam-se os movimentos iniciais da filosofia antiga, principalmente com a figura de Sócrates e os textos de Platão.

PALAVRAS-ChAVE: Ensino de Filosofia; Educação básica; Filosofia antiga. 


\section{The discipline of philosophy in Basic Education and its formative characteristics: a problematization in the light of Ancient Philosophy}

Abstract The purpose of this text is to problematize the limits of philosophy in Basic Education, since, in our analysis, teaching philosophy nowadays provides students with a very impoverished educational background. In fact, what happens in classroom is an educational background that is restricted to the order of comprehension, assimilation and repetition of philosophical discourses. On the one hand, teaching comprises the movement of transmitting representations that the teacher has of a certain fragment in the history of philosophy. On the other hand, learning would be reproducing what has been transmitted, by applying philosophical knowledge as formulas to think about certain issues. From this school context, we begin to problematize the effectiveness of transmission in the construction of a minimally philosophical formation, because it is questioned whether it is the discursive appropriation that would base this formative process. It is hypothesized that it is not the possession of discourses that would guarantee a formation in philosophy and that this way of forming does not find resonance in the own philosophical tradition. For this, the initial movements of the ancient philosophy are recovered, mainly with the figure of Socrates and the texts of Plato.

KEYWORDS: Teaching philosophy; Basic education; Ancient philosophy.

Há alguns anos pesquisando o ensino de filosofia, notamos que a atual condição da disciplina na Educação Básica possui certas características de ensino e aprendizagem circunscritas ao paradigma da transmissão de conhecimentos. Neste artigo, em específico, retomamos essa problematização a partir de nossa experiência no Programa Institucional de Bolsas de Iniciação à Docência (Pibid/Capes). De fato, tal oportunidade constituiu singular experiência formativa, pois nos ofereceu condições de coabitar dois lugares simultaneamente, a saber: do professor com seus desafios e dificuldades envolvidos no ofício; e do observador/pesquisador, cuja função o permite participar das relações de ensino e aprendizagem por um ângulo diferente, sem perder a presença contínua em sala de aula.

Imersos na realidade escolar, começamos a perceber que o ensino de filosofia como transmissão de conteúdos, especialmente ancorado na história da filosofia e no comentário sobre os textos dos filósofos, não possibilitaria o desenvolvimento de uma formação minimamente filosófica ou com aporte filosófico. Isso nos distanciava tanto daquilo que pede os documentos oficiais ${ }^{1}$, que indica que a virtude desse ensino é o senso lógico, argumentativo e, principalmente, uma problematização da realidade face à tradição filosófica, bem como daquilo que almejávamos: a formação filosófica dos estudantes. Assim, um dos entraves que procuraremos desvendar nesse artigo é o problema que o paradigma da transmissão traz às aulas de filosofia na realidade escolar. 
Para melhor entendimento do ensino como transmissão, utilizamos o texto Mestre Ignorante (2011), de Jacques Rancière. Nele encontraremos uma crítica à presente tradição pedagógica que encerra suas possibilidades de ensino na transmissão. Segundo Rancière, a chave de compreensão dessa estrutura educacional passa pela essencial figura do mestre-explicador: imaginem-no como um especialista em determinada área disciplinar, cujo título lhe é conferido pela capacidade de dominar, reter e transmitir uma tradição de conhecimento, didaticamente formalizada em conteúdos. A transmissão se dá, geralmente, pela explicação do conteúdo, partindo dos elementos mais simples, ascendendo aos de maior complexidade. O principal intuito do mestre é passar os alunos de um estado de não saber e ignorância para um estado de sabedoria.

$\mathrm{O}$ ato essencial do mestre era explicar, destacar os elementos simples dos conhecimentos e harmonizar sua simplicidade de princípio com a simplicidade de fato, que caracteriza os espíritos jovens e ignorantes. Ensinar era, em um mesmo movimento, transmitir conhecimentos e formar os espíritos, lendo-os, segundo uma progressão ordenada, do simples ao complexo [...] Assim, raciocinam todos os professores conscienciosos (RANCIERE, 2011, p.19-20).

Engrenagem deste ensino, o mestre-explicador tem como função mediar o processo de conhecer: é ele quem apresenta os signos, mostra os caminhos e, por fim, controla e garante o que será apreendido. Para Pinto e Santos (2013, p. 135), “[...] o mestre explicador se manifesta na figura de um juiz que ministra os conhecimentos a serem emitidos e avalia a recepção destes pelos alunos à sua forma”. Essa relação pode ser visualizada no ensino de filosofia por meio da figura do "[...] professor [que] teria como função ser o mediador entre o filósofo (texto filosófico) e o aluno, objetivando romper a barreira que, supostamente, existe entre aquilo que o aluno leu nos livros de filosofia” (GELAMO, 2009, p. 116). Essa imagem mediadora do professor é reforçada pela própria elaboração do material didático do Programa São Paulo Faz Escola, o qual, desde 2008, é utilizado pela rede pública do Estado de São Paulo e oferecido pela Secretaria da Educação.

Neste material, o Caderno do Professor e o Caderno do Aluno são diferentes, não em conteúdos, mas na explicitação. $\mathrm{O}$ material do professor possui muito mais recursos em termos de conteúdos: apresentam-se mais textos, mais explicações, diversas indicações de leituras e, inclusive, um roteiro de como a aula pode ser conduzida; enquanto que, no material do aluno, poucos são os textos e não há nenhuma sugestão de leitura.

De certa forma, o material fornece ao professor uma "reserva de conhecimento", garantindo que ele tenha mais acesso às informações, se comparado aos alunos. Subentende-se que, por si só, o estudante não possui as condições mínimas para ir ao encontro das informações extras, extraídas de outros textos e, por isso, necessita que o professor apresente determinado assunto ou pensamento filosófico de maneira "simplificada” ou como um conteúdo pronto. Segundo Garcia e Gelamo (2012), a intenção implícita no material didático é suprir o professor com uma reserva de conhecimentos, potencializando sua capacidade de domínio, retenção e transmissão dos conteúdos das aulas. 
A partir das qualidades da proposta do material didático, inclusive da pedagogia tradicional, isto é, quando a função do professor dentro do ensino é de mediação entre o material didático (conteúdo) e o aluno, as aulas apresentam determinadas características estruturais que exprimem tal condição. Com a experiência do PIBID, notamos que o ensino é dividido em situações de aprendizagem com temas atuais ou questões que trazem nuances filosóficas, selecionadas de acordo com a relevância para a formação do jovem aprendiz: temas como a morte, política pública, cuidados com os idosos etc. Os textos de apoio são, na maioria dos casos, fragmentos de textos filosóficos, os quais devem ser explicados, passando pela familiarização com alguns conceitos, até o enunciar da resposta do(s) filósofo(s), para, ao final do processo, ocorrer uma avaliação.

Assim, as aulas de filosofia podem ser divididas do seguinte modo: (1) introdução/questionamento inicial - o professor deve criar uma situação aparentemente conflituosa e relevante, a fim de "despertar" os alunos à reflexão destes questionamentos; (2) resposta aos questionamentos enunciados - o professor fornece a solução para a situação conflituosa: é o momento, por meio da explicação dos fragmentos dos textos filosóficos, de destacar e apresentar os conceitos dos filósofos que podem/devem, aparentemente, aquietar o que se fazia desconfortável; é o ponto auge da relação ensino-aprendizagem; por fim, (3) momento avaliativo - avalia-se o que foi aprendido pela capacidade de articulação dos alunos com aquilo que foi ensinado, isto é, sua capacidade de reprodução discursiva dos conceitos apresentados pelo professor. Quanto mais próximo o discurso do aluno ao do professor, maior é a perfeição de sua atividade, avaliada numa escala de 0 a 10 .

Nessa conjuntura do ensino, em referência à problematização de Rancière (2011), assume o professor o papel de ponte, o ponto de referência que conduz a consciência ignorante à sabedoria. $\mathrm{O}$ professor é aquele que introduz e apresenta as questões conflituosas (as quais já se encontram formuladas), depois oferta as soluções (as respostas que os filósofos criaram para resolver os problemas que lhe competiam). Fatalmente, a construção dos processos formativos é subordinada pela exposição/explicação do professor. É o que, sinteticamente, nos diz Gallo (2012):

\begin{abstract}
Experimentamos ensinar a filosofia à maneira escolástica, isto é, de modo que seja transmitido, de forma organizada e metódica, certo corpus de conhecimento construído ao longo da história. No âmbito de uma didática da filosofia, preocupamo-nos então com a transmissibilidade desses conhecimentos, como transpô-los a fim de que sejam assimiláveis pelos estudantes. Nesse registro, estamos mais preocupados com o ensinar do que com o aprender, uma vez que se toma como premissa que o que é aprendido é aquilo que é ensinado (p. 69).
\end{abstract}

Desse modo, tem-se um ensino de filosofia que aposta menos na construção do problema e no conhecer enquanto processo e, muito mais, na reprodução conceitual dos exímios conceitos filosóficos que se podem transmitir nas relações de sala de aula. Os pressupostos didáticos que sustentam as relações escolares do ensino de filosofia operam como uma estratégia puramente artificial, pois aquilo que é aparentemente conflituoso no presente é apenas tratado como "situação de aprendizagem", a qual se 
enuncia de forma abstrata. $\mathrm{O}$ que realmente está em jogo são os conceitos que devem ser aprendidos a partir dessa suposta relação de questões/respostas. Por assim ser, é válido dizer que esse movimento formativo dentro da sala de aula em nada movimenta o pensamento dos alunos e dos professores, uma vez que o este não lhes pertence, não os afeta e não foi construído por eles.

Por outro lado, ao situar o ensino e a aprendizagem em filosofia sob a ótica da transmissão de conteúdos, acaba-se por circunscrever as práticas do ensino de filosofia na existência de uma realidade comunicativo-representacional, que teoricamente possibilitaria o repasse dos conteúdos (dados-conceitos) de uma consciência que os detém (do professor), para outra consciência que não os possui (do aluno), como se fossem dados informacionais. Na verdade, aquilo que é transferível nessa relação comunicacional são as representações abstratas que o professor tem de determinado pensamento sobre os filósofos e seus sistemas.

Independentemente do lugar de onde se fala, da experiência que se traz, "filosofar" no Ensino Médio é reproduzir discursivamente as representações abstratas dos "sistemas filosóficos" e aplicá-las em determinado contexto escolar. Cria-se, portanto, uma

\begin{abstract}
Imagem distorcida do pensamento filosófico e do filosofar, transmitindo ao aluno não muito mais do que "fórmulas filosóficas" que passam a se constituir em modelos a serem aplicados na resolução de qualquer questão: tal como se utiliza a fórmula matemática para solucionar uma equação cotidiana, as "fórmulas filosóficas" apresentam-se como modelos a se imitar para se pensar criticamente as situações com as quais o aluno depara (GELAMO, 2009, p. 114).
\end{abstract}

Diante dos limites do ensino de filosofia marcado pela transmissão de conteúdos supostamente filosóficos, colocamos o seguinte problema: seria consonante com a tradição filosófica, dimensionado pelo seu percurso histórico de mais de dois mil anos, reduzir a formação filosófica, através do ensino de filosofia, à transmissão de "fórmulas filosóficas" para se pensar criticamente as diversas situações conflituosas do presente, no qual o filosofar propriamente dito estaria restrito ao campo das habilidades de memória, de recognição e reprodução das representações abstratas, engendradas na historicidade dos discursos filosóficos?

Diante desse problema, procuraremos nos enveredar, na tradição filosófica, para a busca de interlocutores que nos possibilitem problematizar a relação ensino e aprendizagem que nos permita conjecturar uma outra maneira de pensar a formação em filosofia no Ensino Médio.

\title{
De Sócrates e Platão à filosofia na antiguidade: uma forma- ção indissociável da vida
}

Até este momento do texto, identificamos que a realidade educacional das instituições de ensino estruturam suas práticas formativas através da transmissão de conhecimentos que foram culturalmente produzidos ao longo da história humana (RANCIÈRE, 2011). A engrenagem dessa grande estrutura de ensino é o mestre 
-explicador - aquele que faz a mediação entre o conhecimento de sua maestria e os alunos. A principal ferramenta deste mestre é a explicação de conteúdos, partindo dos elementos mais simples a serem ensinados, rumo aos mais complexos. Seu objetivo final é a transformação dos alunos, a passagem do estágio simples e ignorante para o estado de sabedoria. Essa tradição está tão incorporada e enraizada nas instituições de ensino, passando de professor a aluno e assim sucessivamente, que dificilmente alguma disciplina/aula escapa desse modelo.

O estabelecimento do ensino de filosofia neste paradigma tradicional o reduz à transmissão dos conceitos dos filósofos da tradição, transformando o conhecimento filosófico num produto acabado e abstrato. Espera-se do aluno uma postura passiva, quase de um telespectador que assimila, memoriza e reproduz as informações expostas em sala de aula. O aprendiz adquire a qualidade de filósofo na medida em que possa se verificar a característica de sua argumentação, isto é, dos conceitos filosóficos que ele repete para se posicionar perante determinadas situações conflituosas. Para nós, esse modo específico que significa a aprendizagem em filosofia, como aquisição e reprodução das abstrações dos discursos filosóficos, não é suficiente para a promoção do filosofar em sala de aula.

Assim, para problematizar essa relação de aprendizagem com a filosofia, fazemos uso da relação que os próprios filósofos da antiguidade tiveram com a filosofia. Para tanto, neste momento, utilizamos o exemplo de Sócrates e Platão, em conjunto com a interpretação de Pierre Hadot e de como ele compreende o fenômeno da filosofia antiga. Mas por que Sócrates?

Apoiados em Kohan (2009), encontramos na figura de Sócrates, a partir da relação estabelecida entre ele e seus discípulos, Platão principalmente, outras construções de sentido em torno do mestre e do aprendiz em filosofia, por meio das quais se faz possível problematizar as significações atuais do estatuto de ensinar e aprender filosofia, e, fundamentalmente, daquilo que se concebe como formação filosófica.

\begin{abstract}
Sócrates é, nesse sentido, um momento inicial e também um limite para todo aquele que ocupa o espaço da transmissão ou do ensino de filosofia. É um duplo impossível, algo assim como um arquétipo que se apresenta a cada vez que um professor de filosofia problematiza o sentido e as condições de sua tarefa (2009, p. 14).
\end{abstract}

Um dos principais motivos reside na própria comparação que Sócrates (Apologia, 23 d) faz de suas atitudes vitais com todos aqueles que filosofam (PLATÃO, 1983, p. 76), isto é, Sócrates constituiu um paradigma para quem quiser, como ele, filosofar. E, ao fazer isso, proporciona uma reinvenção dos lugares dos agentes envolvidos no ensino de filosofia. Especificamente, encontramos em Sócrates que a aprendizagem filosófica não se dá no campo da transmissão, como quer a tradição pedagógica vigente e conforme apresenta Platão no Banquete (175c-e):

Agatão, que se encontrava reclinado sozinho no último leito, exclama:

- Aqui, Sócrates! Reclina-te ao meu lado, a fim de que ao teu contato desfrute eu da sábia ideia que te ocorreu em frente de casa. Pois é 
evidente que encontraste, e que tens, pois não teria desistido antes. Sócrates então senta-se e diz: - Seria bom, Agatão, se de tal natureza fosse a sabedoria que do mais cheio escorresse ao mais vazio, quando um ao outro nos tocássemos, como água dos copos que pelo fio de lã escorre do mais cheio ao mais vazio. (PLATÃO, 1979, p. 10- grifos nossos).

A enigmática figura socrática desenhada por Platão no Banquete instaura a primeira ruptura com a tradição pedagógica: a sabedoria que Sócrates (o filósofo) tanto almeja, e vaga pela pólis para encontrá-la, não é da ordem da transmissão, do transcurso de um produto (sabedoria) daquele que o possui para alguém que não, pois, até Sócrates, houve dois tipos de saber:

De um lado os aristocratas do saber, isto é, os mestres de sabedoria, como Parmênides, Empédocles ou Heráclito, que opunham suas teorias à ignorância da multidão; de outro, os democratas do saber, que pretendiam poder vender o saber a todo mundo: os sofistas (HADOT, 2014a, p.52).

Assim, quando Sócrates pretende saber uma única coisa, que nada sabe, é porque ele recusa a concepção tradicional de saber, o que vai ao encontro de seu método: a ironia e a dialética. Segundo Hadot (2014b), a ironia, eironeiai de Sócrates, por um lado, pode ser interpretada pela condição de pouco valor que ele atribui à sabedoria humana. Nenhuma discussão humana em si mesma deve ser levada totalmente a sério ${ }^{2}$. De outro lado, a ironia socrática consiste numa atitude psicológica de autodepreciar-se, na medida em que finge dar razão momentânea ao interlocutor, ao adotar o ponto de vista com que se dialoga. Através da ironia e da dialética, Sócrates percorre, junto de seu interlocutor, todo o caminho que a discussão conduz. Para tanto, parte daquilo que é próprio de quem com ele dialoga, isto é, busca do saber prático de seu interlocutor, levá-lo a reflexão. Sócrates faz os outros falarem sobre o que dizem, a fim de fazê-los refletir sobre o que realmente fazem. A dialética é uma ferramenta contra o dogmatismo, contra as verdades supostamente cristalizadas. Ele não fala aos outros, mas com eles. Este é o sentido da maiêutica socrática no Teeteto. Nesse texto, Sócrates (150b-c, $151 \mathrm{~b}-\mathrm{c}$ ) anuncia ser possuidor da mesma arte que sua mãe parteira, sendo que ao passo que ela assistia aos nascimentos corporais, ele era parteiro de espíritos. Ele mesmo nada tem a oferecer, é estéril em relação ao conhecimento. Contudo, por meio da dialética, consegue parir a verdadeira sabedoria (PLATÃO, 2001, p. 45-46).

De fato, Sócrates dissocia sua prática da transmissão de uma informação de conhecimentos. Ora, seu discurso não tem como intuito informar, mas formar. $\mathrm{Na}$ tentativa de informar, o discurso passa a ter efeito estritamente unilateral e, por isso, não acompanha o ritmo e as exigências próprias daqueles que estão em investigação. Contudo, a dialética impede o discurso socrático de ser apenas de cunho expositivo e obriga a participação concreta e prática de seu interlocutor. Não se trata de expor uma doutrina. Se assim fosse, Sócrates centralizaria suas relações dialéticas mais em dar respostas do que no próprio ato de interrogar. Por ser ignorante, por não possuir nenhum conteúdo formulado de conhecimento, Sócrates interroga aqueles com quem dialoga e os enche de perturbação de tal modo a levá-los a questionarem a própria vida e, com isso, tenta conduzi-los à tomada de consciência. 
Diferentemente dos mestres habituais, ele deseja que os cidadãos de Atenas, os estrangeiros, velhos ou jovens, aprendam com ele algo muito importante: Sócrates faz de sua vida um constante exame de si e dos outros para que todos com quem ele dialoga transformem seus comportamentos habituais, comecem a cuidar de suas próprias vidas e, consequentemente, das conjunturas da pólis. Assim, mostra-nos Platão (Apologia, 36c), neste trecho:

Não fiquei onde não seria útil, nem a vós, nem a mim, e em vez disso fui a cada um de vós, em particular, servindo-vos o melhor que vos poderia servir. Como disse, tentei persuadir cada um de vós a não cuidar primeiro de si ou das suas coisas, mas cuidar antes do que em cada um de vós é melhor e mais sensato; tal como tentei persuadir cada um de vós a não cuidar primeiro das coisas da cidade, mas cuidas antes da própria cidade, cuidando dos outros como de si (PLATÃO, 1983, p. 93).

Nesse sentido, ao determinar que o saber filosófico não é possível ser formulado discursivamente e, portanto, não se trata de uma condição de apreensão ou não de um conjunto de proposições ditas filosóficas, Sócrates reformula a condição de mestre de seu tempo. Sem um conjunto de proposições para transmitir, pois seu saber não é dessa natureza, Sócrates faz de sua vida e morte seu ensinamento. Em outras palavras, Sócrates transforma sua própria maneira de existir em missão, cujo objetivo é transformar a vida das pessoas, ou seja, de operar uma formação naqueles que com ele convivem. Por essa razão, "[...] a maiêutica socrática inverte totalmente as relações entre mestre e discípulo" (HADOT, 2014b, p. 103) e nos permite, assim, pensar novos elementos que permeiam as relações formativas.

A partir dos apontamentos de seu mestre, na Carta VII, Platão parece, igualmente, negar que a condição do aprendizado filosófico esteja condicionada à transmissão discursiva e a coloca no plano vital de quem pratica e quem aprende filosofia. Para ele, o aprendiz de filósofo deve passar por alguns processos formativos, caso deseje enamorar-se com a filosofia. Antes de qualquer coisa, o aspirante à filosofia deve optar por um gênero de vida, por uma via centrada no desenvolvimento de si. Esse gênero, aliás, demanda um esforço considerável de renovação diária, que se distingue crucialmente da vida daqueles que possuem senão um verniz de opiniões superficiais.

Platão faz alusão a esse gênero de vida quando evoca a figura de Dionísio II, tirano que conheceu através de seu discípulo Dion, no projeto político de Siracusa. Um dos motivos da carta é explicar aos amigos os motivos de sua visita e o desenrolar das questões ali vividas. Platão inquieta-se com a postura tirânica de Dionísio e procura mostrar que este, apesar de pretender-se filósofo, era apenas mais um político tirano que não governava filosoficamente sua cidade. Esse momento da carta retrata os aspectos políticos traçados por Platão à sua filosofia, como diz Hadot (2014a):

A intenção inicial de Platão é política: ele acredita na possibilidade de mudar a vida política pela educação filosófica dos homens influentes da cidade. O testemunho autobiográfico que Platão dá na Carta VII, merece atenção. Ele narra como gostaria, em sua juventude, de se ocupar com os assuntos da cidade e, como descobriu, então, pela morte de Sócrates e por seu exame das leis e dos cos- 
tumes, a que ponto é difícil administrar corretamente os assuntos da cidade, para reconhecer finalmente que todas as cidades de sua época, absolutamente todas, tinham um mau regime político (p. 94)

As razões fundamentais pelas quais Dionísio não era um rei-filósofo diziam respeito à espécie de vínculo que esse tirano tinha com a filosofia. Os erros de Dionísio, segundo Platão, consistiam em (1) acreditar que ele era filósofo, mesmo sem ter uma vida destinada a tal atividade, uma vida que, precisaria alcançar toda a dimensão existencial, desde as atividades mais básicas do cotidiano. Além disso, (2) pensa Dionísio que o fato de reproduzir algumas fórmulas de conhecimento, outrora aprendidas com o próprio Platão, era suficiente para afirmar sua condição de filósofo. Platão, por seu turno, desconfiava dessa possibilidade: “[...] de minha autoria, ao menos, não há nem haverá certamente qualquer escrito sobre tais matérias, dada a impossibilidade de traduzi-las em fórmulas; como sucede com as demais ciências" (PLATÃO, 1962, p. 500).

Para Platão, os erros de Dionísio subsistem pela crença de que o conhecimento filosófico se dava como as demais ciências. Por ser distinto, o conhecimento filosófico não pode ser transmitido e traduzido em fórmulas (mathematas). Caso fosse, Platão argumenta que "se mister fosse expor minha doutrina por escrito ou de viva voz, eu o faria da melhor maneira possível” (PLATÃO,1962, p. 500). No entanto, o filósofo grego continua a afirmar que não cabe ao mestre instituir argumentação com o propósito de fórmulas, a não ser quando se trata de um público restrito, desde que sejam condicionadas a algumas indicações para que, por si, os aspirantes à filosofia descubram a verdade (PLATÃO, 1962, p. 500). Em suma,

Nem a facilidade de aprender nem a memória serão capazes de outorgar o dom de visão a quem não sinta afinidade pelo objeto, pois que ele não pode radicar-se de maneira nenhum em natureza estranha. Donde, tanto os que não sentem inclinação para o justo e para o belo, nem afinidade com estas virtudes, embora dotadas de facilidades de aprender e de reter umas coisas outras, como os que, possuindo essa afinidade, experimentam dificuldades em aprender e são desprovidos de memória, nem uns nem outros chegarão jamais a conhecer, sobre a verdade e sobre o vício tudo quanto é possível aprender (PLATÃO, 1962, p. 502, grifos nossos).

Nesse sentido, Platão procura esclarecer que não é qualquer processo cognitivo que forma o filósofo, mas uma vida fundada num saber-fazer, de procurar viver virtuosamente, inclinado para o justo e o belo, vida esta que, evidentemente, não se separa dos atos cognitivos de conhecimento. Na Carta VII, Platão indica alguns exercícios que perpassam o processo filosófico, o qual se dá através dos nomes dos objetos, de suas definições, das imagens que lhe pertencem, das impressões sensitivas e percepções visuais que se pode dele ter, até o dialogo pacífico, isto é, acordado no lógos como fundamento, entre diferentes interlocutores. Somente depois de todos esses exercícios sobre o objeto estudado que "[...] começa a brilhar a luz da sabedoria e da inteligência com a intensidade capaz de ser suportada pelas forças humanas" (PLATÃO, 1962, p. 503). 
Sócrates e Platão representam um ponto de uma tradição filosófica que une pensamento e vida, cujos processos formativos diferenciam-se drasticamente daqueles que permeiam a relação formativa com a filosofia na Educação Básica. $\mathrm{Na}$ filosofia antiga, a formação filosófica nunca é retomada como um ato estrito de conhecimento, como um processo restrito ao intelectivo, entre o sujeito e o conhecimento. Ao contrário, constitui como uma prática que não prescinde da experiência e que necessita de uma série de exercícios do próprio aprendiz para modelar-se para apreensão da sabedoria. Segundo Hadot (2014a), o que a filosofia antiga busca é identificar-se com um saber-fazer, um saber virtuoso, que busca uma transfiguração daquele que a pratica:

Pode-se admitir que a sabedoria representa a perfeição da sabedoria identificado à virtude. Mas, como já dissemos e deveremos tornar a dizê-los, na tradição grega o saber ou sophia é menos um saber puramente teórico que um saber-fazer, um saber-viver, e nele se reconhecerão traços da maneira de viver, não o saber teórico, de Sócrates filósofo, que Platão evoca precisamente no Banquete (p. 76).

Afinal, não é essa pretensão que se tem quando se imagina a filosofia dentro da escola? Não se busca um ensino que desenvolva as potencialidades dos alunos, que lhes possibilite um desenvolvimento crítico e uma transformação na forma de viver? Ser crítico, ser um cidadão é possuir argumentos, carregar uma gama de discursos, ou é viver virtuosamente numa maneira de vida que se posiciona criticamente perante a contemporaneidade? Portanto, não seria mais razoável trazer a filosofia como uma tradição de pensamento que auxilie e impulsione na construção dos problemas contemporâneos, do que como uma razão que traz fórmulas prontas para resolver aquilo que é possivelmente conflituoso?

No entanto, atualmente, há uma diferenciação do trabalho filosófico da maneira de se fazer filosofia no período antigo. Isso porque, segundo Hadot (2014a) há uma profunda diferença entre "[...] a representação que os antigos faziam da filosofia e a representação que se faz habitualmente da filosofia em nossos dias, pelo menos na imagem transmitida aos estudantes" (2014a, p.16-17). Atualmente, as academias de filosofia estão extremamente restritas à particularidade discursiva da atividade filosófica, o que refletirá decisivamente na condição da filosofia no Ensino Médio. No momento, o trabalho filosófico é condicionado pelo estudo, leitura e comentário sobre os textos filosóficos. Busca-se o rigor metodológico na leitura, com a tentativa de reconstruir uma doutrina segundo a mente do autor, isto é, de lançar uma hipótese interpretativa para apreender o significado do escopo do sistema filosófico. Busca-se refazer os movimentos filosóficos para aprender sua lógica interna (PEREIRA, 2010, p. 19). Por essa razão, o campo filosófico encontra-se preso ao nível discursivo, em detrimento de outras dimensões que também abarcariam esta tradição.

Aos olhos de Hadot, é comum que os estudantes tenham a impressão de que os filósofos esforçaram-se para inventar, cada um de uma maneira original, uma nova construção sistemática e abstrata, com o intuito de explicar o universo e a realidade (HADOT, 2014a, p. 17). A filosofia, em si mesma, seria apenas um esforço intelectual e discursivo do pensamento humano, confundindo-se com uma prática estritamente teórica. Contudo, é um equívoco dimensionar a filosofia antiga nesses termos. Não se 
trata de negar a capacidade dos filósofos de elaborarem e desenvolverem as reflexões teóricas, mas de destacar que a atividade discursiva só faz sentido quando emerge intrinsecamente vinculada a um modo de vida. Antes de qualquer coisa, segundo $\mathrm{Ha}-$ dot, a filosofia do período antigo é marcada por um modo de vida que, resultante de uma oposição crítica ao modo predominante de viver, exige o desenvolvimento de um discurso filosófico.

O discurso filosófico deve ser compreendido na perspectiva do modo de vida no qual ele é ao mesmo tempo o meio e a expressão e, em consequência, que a filosofia é, antes de tudo, uma maneira de viver, mas está estritamente vinculada ao discurso filosófico (2014a, p. 18).

Diferentemente dos aspectos discursivos que tem a filosofia atual, Hadot aponta que a dimensão discursiva da filosofia antiga assume três facetas na atividade filosófica:

(1) justifica teoricamente o modo de vida: de uma extremidade à outra da história da filosofia antiga, os filósofos recorrem ao discurso como ferramenta para desembaraçar os pressupostos assumidos, as implicações e as consequências das decisões teóricas tomadas na filosofia como modo de vida (HADOT, 2014a, p. 253).

(2) o discurso é um meio privilegiado a partir do qual o filósofo pode agir sobre si mesmo e sobre os outros, “[...] pois, se ele é a expressão de uma opção existencial daquele que o sustenta, sempre tem, direta ou indiretamente, uma função formadora, educadora, psicagógica, terapêutica” (HADOT, 2014a, p. 254).

(3) O discurso é uma forma de exercício da filosofia antiga, como a filosofia de Platão, por exemplo, na qual, por meio dos diálogos, buscava-se no discurso o recurso à verificação dos limites dos conhecimentos que os interlocutores acreditam possuir, incentivando a criar um habitus em conformidade com os princípios assumidos. Por essa razão, na filosofia como maneira de viver, não se pode opor opção existencial e discurso como se eles correspondessem, respectivamente, à prática e à teoria, uma vez que o discurso pode ter um aspecto prático quando condicionado como um exercício de conversão.

Tudo isso só faz sentido com base no pressuposto de que a filosofia antiga parece estar fundada no objetivo de uma transformação espiritual ligada ao modo de viver, isto é, de relacionar-se com a vida, com os outros e com a sabedoria.

Para se transformarem espiritualmente, os filósofos utilizavam uma série de práticas, intituladas por Hadot como askésis e meletê - práticas voluntárias e pessoais destinadas a operar uma transformação no "eu". Cada escola de filosofia tem seus exercícios distintos, mas todas partem conceitualmente da filosofia como uma prática, um saber como, buscando uma modificação em todos os níveis daquele que a pratica (2014b, p. 23). Assim,

Nesta perspectiva, o ensino filosófico tende a tomar a forma de uma predicação na qual os meios da retórica ou da lógica são postos a serviço da conversão das almas. A filosofia antiga, portanto, não 
é jamais a edificação de um sistema abstrato, mas aparece como um apelo à conversão por meio da qual o homem reencontrará sua natureza original (epistrophè) em um violento desenraizamento da perversão na qual vive o comum dos mortais e numa profunda reviravolta de todo o ser. (HADOT, 2014b, p. 206).

Nesse sentido, as condições formativas presentes no período antigo da filosofia, principalmente, a partir das figuras de Sócrates e Platão aqui analisadas, almejavam potencializar uma transformação nos hábitos vitais de quem se dedicava à filosofia. Para tanto, o discurso (na filosofia antiga) não tem como função transmitir conhecimentos representacionais, mas proporcionar uma relação de exercícios espirituais modeladores do "ser" que busca viver filosoficamente. Desse modo, podemos dizer que o conhecimento filosófico, em sua natureza, tem a característica de um saber fazer, isto é, de um saber viver, propriamente dito. Sócrates, por exemplo, não ensina nada que esteja fora de sua vida e de sua forma de viver. Não há um discurso externo, alheio à sua condição vital. Sua própria vida é um ato pedagógico, desde sua postura crítica, até a forma como dispõe seu discurso.

Platão, do mesmo modo, parece levar a sério as críticas de seu mestre à sabedoria e formação de seu tempo. Em sua experiência formativa com Dionísio II, não orienta seu ensino enquanto um discurso representacional, que transcende as condições da vida de quem ensina e de quem aprende. Pelo contrário, tornar-se um aprendiz de filosofia é envolver-se em dois momentos: (1) do ato de conhecimento, dos processos epistemológicos e (2) a transformação de si por meio de uma série de exercícios que permitam à apreensão da verdade.

\section{Considerações finais: o retorno da vida à formação filosófica}

Imaginamos que o leitor deve estar se questionando em que medida o ensino de filosofia aos moldes da filosofia antiga pode ser viabilizado na atual realidade escolar. Com as salas de aulas cada vez mais lotadas, com pouco tempo para se trabalhar, seria muito complicado pensar as aulas de filosofia em termos de exercícios espirituais, do modo como ocorria nas práticas antigas com a filosofia. As duas aulas semanais poderiam ser um contraponto relevante para contradizer uma relação filosófica que ocorria entre cidadãos gregos e livres numa sociedade escravocrata. Porém, não é a transposição descontextualizada que queremos trazer. Não se trata de dar uma fórmula ou de simplesmente comunicar aos professores e alunos a maneira pela qual devem construir suas aulas de filosofia.

Com a crítica elaborada por Rancière (2011), foi possível notar que algumas das práticas de ensino de filosofia são fundamentadas no pressuposto formativo de que formar é transmitir conhecimentos. Sob o pressuposto da transmissão, a formação filosófica está ancorada na figura do professor, que justifica seu papel pela ascendência de conhecimento que possui, em contraposição à suposta ignorância do aluno. No entanto, Sócrates e sua ignorância recolocam o professor de filosofia em outro patamar, que já não é mais da ascendência discursiva. Não é dessa natureza o conhecimento que possui. Sócrates não sabe o que é justiça, o belo e o bem de modo discursivo. Ele vive 
aquilo que acredita que é justo, belo e bom. Sua sabedoria é seu modo de viver e seu ensinamento é uma afronta ao modo de viver ateniense. Desse modo, tampouco importaria aos ouvintes de Sócrates saber no âmbito discursivo o que é justiça, ou saber o que é o bem. Talvez Sócrates já tivesse atentado a essa impossibilidade nos diálogos aporéticos. No entanto, possível ou não, a posse de um discurso não lhes outorgaria o saber filosófico, isto é, um saber viver.

Contudo, mesmo não sendo de natureza discursiva o conhecimento filosófico, Sócrates não abre mão daquilo que é discursivo em uma prática filosófica. A maiêutica socrática é fundamental para justificar sua vida, pois seu discurso não informa, mas forma. Por isso, sua prática discursiva reafirma a condição de um mestre que não possui nenhum conhecimento, mas atenta e impele seus ouvintes para a ignorância que também devem reconhecer. Trata-se, assim, de vidas a serem modificadas e não discursos a serem adquiridos.

Por sua vez, Platão também desloca a formação filosófica de Dionísio II de um processo estritamente cognitivo de transmissão de um suposto conhecimento filosófico por meio do discurso formulado tanto no âmbito da fala quanto da escrita. Nesse sentido, a substancialidade do pensamento de Platão contido na Carta VII, condicionaria a formação filosófica perspectivada mais por um conjunto de práticas que se realiza enquanto vida do que pela aquisição e repetição de fórmulas de conhecimentos, confundidas como as proposições de determinados filósofos sobre algo. É desse modo que também interpreta Pierre Hadot o fenômeno da filosofia antiga: a filosofia enquanto um saber viver de modo virtuoso que é adquirido por meio de uma série de exercícios espirituais, dentre os quais o discurso possui papel fundamental.

Com efeito, para responder o problema inicial, não são práticas de reprodução, assimilação e compreensão dos conteúdos discursivos daquilo que se define como história da filosofia que sustentariam uma formação filosófica. Pelo menos na tradição da filosofia antiga, em oposição à tradição pedagógica da transmissão, o conhecimento filosófico assume outra natureza, a qual irrompe com os limites de uma formulação discursiva. Assim como os alunos não adquirirão potenciais minimantes filosóficos ao possuir os discursos dos filósofos, também os professores não trarão potencialidades filosóficas às salas de aulas só por dominar algumas dessas representações abstratas sobre a tradição de pensamento da filosofia.

Em termos práticos, pensamos que, com o destaque para a filosofia antiga, um novo paradigma de pensamento se abre e, com ele, a tentativa de resgatar a subjetividade de quem aprende e de quem ensina nas práticas formativas, algo que foi se apagando historicamente nas práticas de ensino de filosofia. Trata-se da possibilidade de formar-se de modo processual, por meio de práticas que não excluem o discurso, mas também não se restringem a ele. De um lado, a sala de aula não pode mais ser o lugar em que a realidade e a vida daqueles que atuam na construção do ensino de filosofia na escola sejam apenas meros mecanismos didáticos que só permitam a exposição conceitual, o simples discurso informacional. 
O professor de filosofia não deve ser mais o mediador de uma história de conhecimentos que só podem ser acessados enquanto representações abstratas. Para exigir que o aluno se transforme, espera-se do professor que filosofe em sala de aula, que traga a tradição filosófica e a tensione com o presente, construindo uma realidade problemática dentro das salas de aulas, em que sua vida e a dos alunos sejam transformadas. Afinal, como o professor de filosofia poderá exigir de seu aluno uma transformação filosófica se ele, no exercício de seu ofício, se recusa a filosofar?

O caso é atentarmo-nos à necessidade contemporânea de trazer a vida para a formação filosófica e, para tanto, já não basta trazer a tradição filosófica enquanto um conjunto de discursos filosóficos abstratos que não se inter-relacionam com a vida do professor e do aluno.

\section{Referências}

BRASIL. Lei Federal no 11.684, de 02 de junho de 2008. Altera o art. 36 da Lei no 9.394, de 20 de dezembro de 1996, que estabelece as diretrizes e bases da educação nacional, para incluir a Filosofia e a Sociologia como disciplinas obrigatórias nos currículos do ensino médio. Disponível em: <http:/www.planalto.gov.br/ccivil_03/_ato2007-2010/2008/lei/111684.htm>. Acessado em: 12 mar. 2018.

BRASIL. Secretaria de Educação Básica. Orientações Curriculares de Filosofia (OCEM). Brasília: MEC/SEB, 2006. Disponível em: http://portal.mec.gov.br/seb/arquivos/pdf/book_ volume_03_internet.pdf. Acessado em: 12 mar. 2018.

BRASIL. Secretaria da Educação Média e Tecnológica. Parâmetros Curriculares Nacionais: ensino médio. Brasília: MEC/SEMTEC, 2002.

CERLETTI, Alejandro. O ensino da filosofia como problema filosófico. Trad. Ingrid Müller Xavier. Belo Horizonte: Autêntica Editora, 2009.

FINI, Maria Inês. (Org.). Caderno do professor: filosofia, ensino médio. São Paulo: SEE, 2009.

GALLO, Silvio Donizetti de Oliveira. Metodologia do ensino de filosofia: Uma didática para o ensino médio. Campinas: Papirus, 2012.

GARCIA, Amanda Veloso., GELAMO, Rodrigo Pelloso. Repensando o lugar da representação, da transmissão e da experiência no ensino de filosofia. Filosofia e Educação; Campinas, v. 4, n. 1, abril-setembro de 2012. Disponível em: <https://periodicos.sbu.unicamp.br/ojs/index. $\mathrm{php} / \mathrm{rfe} / \mathrm{article} / \mathrm{view} / 8635437>$. Acesso em: 12 mar 2018.

GELAMO, Rodrigo Pelloso. Ensino da filosofia no limiar da contemporaneidade: $O$ que faz o filósofo quando o seu ofício é ser professor de filosofia? São Paulo: Cultura Acadêmica, 2009. Disponível em: http://www.culturaacademica.com.br/_img/arquivos/\%7BDE44A0D11710-4F9B-B0F8-347122201111\%7D_Ensino_da_filosofia_limiar_da_contemp-NOVA\%20 P4.pdf. Acesso em: 12 mar. 2018.

HADOT, Pierre. (1999). O que é filosofia Antiga? Trad: Dion Davi Macedo, São Paulo: Edições Loyola, Brasil, 2014a (6 ${ }^{\mathrm{a}}$ edição).

HADOT, Pierre. Exercícios espirituais e filosofia antiga. Trad: Flavio Fontenelle Loque e Loraine Oliveira, São Paulo: É Realizações, 2014b.

KOHAN, Walter Omar. Filosofia: o paradoxo de aprender e ensinar. Trad. de Ingrid Müller Xavier. Belo Horizonte: Autêntica, 2009. (Coleção Ensino de Filosofia)

PLATÃO. Carta VII: Platão aos parentes e amigos de Díon. Saudações. In: Revista Brasileira de Filosofia, v. 12, n. 48, p. 486-509, out./dez. 1962. 
PLATÃO. Êutifon, Apologia de Sócrates, Críton. 4. ed. Lisboa: Casa da Moeda, 1983. Tradução, Introdução e Notas de José Trindade Santos

PLATÃO. Banquete. Diálogos. Trad. e notas de José Cavalcante de Souza. 2. ed. São Paulo: Abril Cultura, 1979 (Os Pensadores).

PLATÃO. Teeteto. Diálogos. Trad: Carlos Alberto Nunes. 3. ed. Belém: Editora Universitária UFPA, 2001.

PEREIRA, Oswaldo Porchat . Discurso aos estudantes sobre a pesquisa em filosofia. Fundamento, v. 1, n. 1, set-dez, 2010. Disponível em: http://www.revistafundamento.ufop.br/index. php/fundamento/article/view/13>. Acesso em: 12 mar. 2018

PINTO, Silmara Cristiane., SANTOS, Genivaldo de Souza Experiência e aprendizagem no ensino de filosofia. Filogênese, Marília, v. 6, n. 2, 2013. Disponível em: http://www.marilia. unesp.br/Home/RevistasEletronicas/FILOGENESE/silmaraegenivaldo.pdf>. Acesso em: 12 mar. 2018.

RANCIÈRE, Jacques. O mestre ignorante: cinco lições sobre a emancipação intelectual. Trad: Lílian do Valle. 3 ed. Belo Horizonte: Autêntica Editora, 2011.

SILVA, FranklinLeopoldo. História da Filosofia: Centro ou referencial? In: NETO, Henrique Nielsen (org.) $O$ ensino de filosofia no ${ }^{\circ}{ }^{\circ}$ grau. São Paulo: SOFIA Editora SEAF, 1986, p.153162.

\section{Notas}

\footnotetext{
${ }^{1}$ Segundo as Orientações Curriculares para o Ensino Médio (2006, p. 29) "o objetivo da disciplina Filosofia não é apenas propiciar ao aluno um mero enriquecimento intelectual. Ela é parte de uma proposta de ensino que pretende desenvolver no aluno a capacidade para responder, lançando mão dos conhecimentos adquiridos, as questões advindas das mais variadas situações. Essa capacidade de resposta deve ultrapassar a mera repetição de informações adquiridas, mas, ao mesmo tempo, apoiar-se em conhecimentos prévios. Por exemplo, caberia não apenas compreender ciências, letras e artes, mas, de modo mais preciso, seu significado, além de desenvolver competências comunicativas intimamente associadas à argumentação." Utilizamos como referência as próprias Orientações, uma vez que, conforme consta no documento, ela retoma e rediscute os Parâmetros Curriculares Nacionais- Ensino Médio (2002), de maneira oferecer subsídios para efetivamente consolidar a filosofia enquanto disciplina componente curricular do ensino médio (BRASIL, 2006, p. 20).

2 "Na verdade, não se trata de uma atitude artificial, de um parti pris de dissimulação, mas de uma espécie de humor que recusa levar totalmente a sério tanto os outros como a si mesmos, porque, precisamente, tudo que é humano, e mesmo tudo o que é filosófico, é coisa bem pouco assegurada, de que não se pode ter muito orgulho" (HADOT, 2014a, p. 52)
}

* Mestrando no Programa de Pós-Graduação pela Educação da Universidade Estadual Paulista Júlio de Mesquita Filho, Campus de Marília, Marília, São Paulo, Brasil.

** Doutor Docente do Programa de Pós-graduação em Educação - Departamento de Didática- da Universidade Estadual Paulista Júlio de Mesquita Filho, Campus de Marília, Marília, São Paulo, Brasil. 
Augusto Rodrigues - Rodrigo Pelloso Gelamo

\section{Correspondência}

Augusto Rodrigues - Universidade Júlio de Mesquita Filho - UNESP, Departamento de Didática. Av. Higino Muzzi Filho,737, Cidade Universitária. CEP: 79117900. Marília, São Paulo, Brasil.

E-mail: augustorodrigues094@gmail.com - gelamo@gmail.com

Recebido em 07 de dezembro de 2017

Aprovado em 20 de março de 2018 